\title{
Protective effect of remote ischemic pre-conditioning on patients undergoing cardiac bypass valve replacement surgery: A randomized controlled trial
}

\author{
XIULING JIN, LIANGRONG WANG, LILING LI and XIYUE ZHAO \\ Department of Anesthesiology, The First Affiliated Hospital of Wenzhou Medical University, \\ Wenzhou, Zhejiang 325000, P.R. China
}

Received February 5, 2018; Accepted December 28, 2018

DOI: $10.3892 /$ etm.2019.7192

\begin{abstract}
Remote ischemic pre-conditioning (RIPC) may have a protective effect on myocardial injury associated with cardiac bypass surgery (CPB). The objective of the present study was to investigate the effect of RIPC on ischemia/reperfusion (I/R) injury and to assess the underlying mechanisms. A total of 241 patients who underwent valve replacement were randomly assigned to receive either RIPC $(n=121)$ or control group $(n=120)$. The primary endpoint was peri-operative myocardial injury (PMI), which was determined by serum Highly sensitive cardiac troponin $\mathrm{T}$ (hsTnT). The secondary endpoint was the blood gas indexes, acute lung injury and length of intensive care unit stay, length of hospital stay and major adverse cardiovascular events. The results indicated that in comparison with control group, RIPC treatment reduced the levels of hsTnT at 6 and 24 h post-CPB $(\mathrm{P}<0.001)$, as well as the alveolar-arterial oxygen pressure difference and respiratory index after CPB. Furthermore, RIPC reduced the incidence of acute lung injury by $15.3 \%$ (54.1\% in the control group vs. $41.3 \%$ in the RIPC group, $\mathrm{P}=0.053$ ). It was indicated that $\mathrm{RIPC}$ provided myocardial and pulmonary protection during CPB. In addition, the length of the intensive care unit and hospital stay was reduced by RIPC. Mechanistic investigation revealed a reduced content of soluble intercellular adhesion molecule-1, endothelin-1 and malondialdehyde, as well as elevated levels of nitric oxide in the RIPC group compared with those in the control group. This indicated that RIPC protected against I/R injury associated with CPB through reducing the inflammatory response and oxidative damage, as well as improving pulmonary vascular tension. In conclusion, RIPC reduced myocardial and
\end{abstract}

Correspondence to: Dr Xiyue Zhao, Department of Anesthesiology, The First Affiliated Hospital of Wenzhou Medical University, 3 Yuanxi Road, Lucheng, Wenzhou, Zhejiang 325000, P.R. China

E-mail: zxy_xiyuezhao00@163.com

Key words: remote ischemic pre-conditioning, ischemia/reperfusion injury, cardiac bypass surgery pulmonary injury associated with $\mathrm{CPB}$. This protective effect may be associated with the inhibition of the inflammatory response and oxidative injury. The present study proved the efficiency of this approach in reducing ischemia/reperfusion injury associated with cardiac surgery. Clinical trial registry no. ChiCTR1800015393.

\section{Introduction}

Heart surgery with cardiopulmonary bypass (CPB) is a primary treatment strategy for patients with coronary artery disease. As blood circulation in the myocardium is avoided during heart surgery, ischaemia-reperfusion (I/R) injury may occur during cardioplegic arrest.

A prominent characteristic of ischaemic injury is a reduced vascular endothelium-dependent vasodilation. Nitric oxide (NO) (1) and endothelin-1 (ET-1) (2) are two critical endothelium-derived factors. NO has a fundamental biological role in protecting organs (such as the heart) against I/R injury (3-5). In particular, the protective role of NO in the heart (6) and kidney (7) have been proven. Furthermore, the generation of ET-1 is aggravated under ischaemic conditions (8). In addition, substantial evidence has indicated that $\mathrm{I} / \mathrm{R}$ injury associated with CPB is in closely linked with the systemic inflammatory response (SIRS) $(9,10)$. The important roles of inflammation have also been reported in the pathogenesis of brain ischemia (11-13). Various inflammatory factors, including soluble intercellular adhesion molecule-1 (sICAM-1) and ET-1 (14), participate in inflammatory processes. Furthermore, oxidative stress contributes to the pathogenesis of I/R injury (15).

It has been proved that the production of oxygen radicals is directly associated with major tissue and organ damage (16). Furthermore, toxic oxygen metabolites, including the lipid peroxidation product malondialdehyde (MDA) (17), exert damaging effects on multiple pathophysiological processes.

Peri-operative myocardial injury (PMI) is a type of injury that typically occurs in patients who received valve surgery (18). Furthermore, due to the effects of anesthetic drugs and mechanical ventilation, pulmonary compliance of the patients gradually decreases with the time of ventilation progressing. During CPB, the pulmonary function is impaired by the continuous low perfusion of the lungs and pre-flush-mediated blood dilution (19). 
Such lung I/R injury may affect the functions of other organs in the patients after the operation.

Based on these investigations, it is necessary to develop effective therapeutic interventions so as to protect against tissue injury (20). Remote ischaemic pre-conditioning (RIPC) has been recognized as a low-cost, non-invasive intervention method by applying brief ischaemia and reperfusion on an arm or a leg. RIPC exerts protective effects on remote tissue or organs against lethal acute I/R injury (21-24). RIPC may be achieved by performing a standard blood-pressure cuff (25). While the effect is not obvious under certain conditions (25-27), application of RIPC has produced beneficial outcomes in patients who received open-heart surgery (27-30) or coronary intervention (31). In addition, the protective effect of RIPC on the kidney has been previously demonstrated (32). However, whether RIPC has the capacity to prevent myocardial and lung $\mathrm{I} / \mathrm{R}$ injury has remained to be fully demonstrated.

The overall objective of the present study was to investigate the protective effect of RIPC on myocardial and lung I/R injury. Furthermore, the present study aimed to elucidate the possible underlying mechanisms.

\section{Materials and methods}

Study design. The present randomized controlled trial was approved by the Ethics Committee of the First Affiliated Hospital of Wenzhou Medical University (Wenzhou, China). Written informed consent was received from each patient included in the study. Patients who received valve surgery at the First Affiliated Hospital of Wenzhou Medical University (Wenzhou, China) between July 2012 and July 2015 were recruited. The inclusion criteria were mitral valve disease, aortic valve disease or combined valvular disease and patients with stable hemodynamic blood. The exclusion criteria were, infection, chronic lung disease, medications that may interfere with RIPC, pregnancy, renal disease, cardiac arrest during hospital admission and peripheral arterial disease affecting the limbs, complicated coronary heart disease, complicated hypertension, congenital heart valve disease, preoperative stroke, simultaneous radiofrequency ablation of atrial fibrillation and reoperate. The recruited patients were randomly divided into two groups. In the grouping process, the information regarding treatment allocation was delivered by a nurse who was not involved in the study. The investigators who analyzed the data were blinded to the treatment allocation.

Intervention. In the RIPC and control groups, surgery was initiated after anaesthesia and completed prior to sternotomy. An intense multi-limb method was performed consisting of two 5-min cycles of simultaneous upper arm and thigh cuff inflation and deflation (simultaneous inflation to $200 \mathrm{mmHg}$, left inflation for $5 \mathrm{~min}$ and then deflation to $0 \mathrm{mmHg}$ and left deflated for $5 \mathrm{~min}$ ) (32). In the control group, patients were not subjected to any preconditioning. The intervention was performed without any arterial line on the arm, and the blood-pressure cuffs on the arms were bound up.

Anesthesia and surgical protocol. Patients were intramuscularly injected with $0.3 \mathrm{mg} / \mathrm{kg}$ scopolamine and $0.2 \mathrm{mg} / \mathrm{kg}$ morphine at $0.5 \mathrm{~h}$ prior to the surgery. All patients were routinely monitored via electrocardiogram, non-invasive blood pressure, invasive radial arterial pressure, heart rate and respiration using a multifunctional monitor. Anaesthesia was induced with imidazole valium $(0.1 \mathrm{mg} / \mathrm{kg})$, sufentanyl $(0.5 \mu \mathrm{g} / \mathrm{kg})$, vucuronium bromide $(0.15 \mathrm{mg} / \mathrm{kg})$ and propofol $(2.0 \mathrm{mg} / \mathrm{kg})$. Mechanical ventilation was maintained by a Datex-Ohmeda Aestiva/5 anaesthesia machine (GE Healthcare, Little Chalfont, UK) with the tidal volume set at $8-10 \mathrm{ml} / \mathrm{kg}$ and the suction/call ratio set at 1:2. The normal-end tidal carbon dioxide pressure was maintained at $26-32 \mathrm{mmHg}$ by setting the respiratory frequency at $11-13$ breaths/min. Myocardium was protected by perfusion of cold blood cardioplegia. The concentration of $\mathrm{K}^{+}$was 23-24 mmol/1. Surgery was performed with a median sternal incision. The distal ascending aorta was inserted into the arterial infusion tube. The superior and inferior venas cava were inserted into the vena cava drainage tube. The aortic valve was replaced with the atrial cavity tube, and the right superior pulmonary vein was placed in the left cardiac drainage to establish extracorporeal circulation. Mitral valve replacement was performed through the right atrial septal incision, with continuous or intermittent sutures. Aortic valve replacement was performed through the aortic root incision with intermittent suture. If the tricuspid valve has a lesion, it may be shaped or replaced at the same time. A standard CPB was performed using the Stöckert SIII perfusion system (Stöckert GmbH, Munich, Germany), which was followed by valve replacement. The surgery was completed and protamine was employed to achieve heparin reversal (protamine/heparin, 1-1.2:1).

Primary and secondary endpoints. The primary endpoint of the present study was PMI. Highly sensitive cardiac troponin $\mathrm{T}$ (hsTnT) was detected as a marker for PMI. Furthermore, the present study had two secondary endpoints, one of which were the blood gas indexes, acute lung injury (ALI) and length of intensive care unit (ICU) stay, while the other one was length of hospital stay and major adverse cardiovascular events at 90 days (death, myocardial infarction or stroke).

Detection of serum markers. Blood samples were collected pre-operatively (T1) and at $5 \mathrm{~min}$ (T2), 2 h (T3), 6 h (T4) and $24 \mathrm{~h}$ (T5) after CPB. hsTnT was quantitated by one-step enzyme immunoassay technology (Elecsys 2010; Roche Diagnostics, Basel, Switzerland) as described previously (33). hsTnT levels of $\geq 14 \mathrm{ng} / \mathrm{l}$ were considered to indicate severe myocardial injury. The content of sICAM-1 was determined by ELISA (sICAM-1; cat. no. 48T96T; Xitang Biotechnology, Shanghai, China) and the optical density value was recorded by a microplate reader (Multiskan Spectrum; Thermo Fisher Scientific, Inc., Waltham, MA, USA). Furthermore, the level of ET-1 was detected using an immunoassay (ET-1; cat. no. 990826; Beijing Institute of East Asian Institute of Immunology, Beijing, China) according to the manufacturer's protocol. The contents of MDA and NO were measured using spectrophotometrical assays (MDA, cat. no. A003-1; NO, cat. no. A013-2; Nanjin Jiancheng Bioengineering Institute, Jiangsu, China).

Blood gas analysis and ALI estimation. Alveolar-arterial oxygen pressure difference $\left[\mathrm{P}\left(\mathrm{A}-\mathrm{aDO}_{2}\right)\right]$ and respiratory index (RI) were considered as blood gas indexes. The partial oxygen 
pressure $\left(\mathrm{PaO}_{2}\right)$, partial $\mathrm{CO}_{2}$ pressure $\left(\mathrm{PaCO}_{2}\right)$ and fraction of inspired oxygen $\left(\mathrm{FiO}_{2}\right)$ were recorded using an i-STAT (Abbott, Princeton, NJ, USA) and used to calculate the $\mathrm{P}\left(\mathrm{A}-\mathrm{aDO}_{2}\right)$ and RI using the following formulas: $\mathrm{P}\left(\mathrm{A}-\mathrm{aDO}_{2}\right)=\left(\mathrm{Patm}-\mathrm{PH}_{2} \mathrm{O}\right)$ X $\mathrm{FiO}_{2}-\mathrm{PaCO}_{2} / \mathrm{R}-\mathrm{PaO}_{2}$ and $\mathrm{RI}=\mathrm{P}\left(\mathrm{A}-\mathrm{aDO}_{2}\right) / \mathrm{PaO}_{2}$, where Patm is the atmospheric pressure of $760 \mathrm{mmHg}$ and $\mathrm{PH}_{2} \mathrm{O}$ is the water vapor pressure of $47 \mathrm{mmHg}$. ALI was estimated according to the diagnostic criteria of American-European Consensus Conference on the acute respiratory distress syndrome/ALI (34): i) $\mathrm{PaO}_{2} / \mathrm{FiO}_{2}<300 \mathrm{mmHg}$; ii) no atelectasis, no pleural effusion and no pneumothorax; and iii) no congestive heart failure.

Statistical analysis and sample size estimation. Values are expressed as the mean \pm standard deviation. Comparison between groups was performed using Student's t-test or Wilcoxon Mann Whitney test for continuous variables that were normally or distributed or not, respectively. The Chi-squared and Fisher's Exact test were used for discontinuous variables. Two-way analysis of variance followed by Bonferroni's post-hoc test was used to analyze differences among groups for serum markers collected at different time-points. Assuming a statistical power of $90 \%$ and a type I error rate of $5 \%$, this required a sample size of 120 subjects (which accommodated withdrawal or missing data-points). SPSS 20.0 (IBM Corp., Armonk, NY, USA) and GrahPad Prism 5 (GraphPad Inc., La Jolla, CA, USA) were used to analyze the data. $\mathrm{P}<0.05$ was considered to indicate a statistically significant difference.

\section{Results}

Patients. A total of 280 patients were assessed for recruitment eligibility, and 241 patients were finally enrolled and assigned to the RIPC $(n=121)$ or control $(n=120)$ group (Fig. 1). With regard to the basic characteristics, no significant difference was identified between the two groups (Table I). Furthermore, no adverse events (death, myocardial infarction or stroke) associated with the RIPC protocol were observed.

Effect of RIPC on myocardial injury and lung injury. The baseline hsTnT levels in the two groups were similar and no significant difference was observed. It was identified that the levels of hsTnT in the RIPC group were reduced at 6 and $24 \mathrm{~h}$ post-CPB as compared with those in the control group $(\mathrm{P}<0.05$, Fig. 2). $\mathrm{P}\left(\mathrm{A}-\mathrm{aDO}_{2}\right)$ and $\mathrm{RI}$ are direct indicators of pulmonary ventilation and oxygenation function (35), and these two parameters exhibited an increasing trend at first, followed by a gradual decline gradual after CPB was performed in each of the two groups [the decline occurred: $\mathrm{P}\left(\mathrm{A}-\mathrm{aDO}_{2}\right)$, T4; RI, RIPC, T5, Control, T4]. After $\mathrm{CPB}$, the $\mathrm{P}\left(\mathrm{A}-\mathrm{aDO}_{2}\right)$ was identified to be significantly lower in the RIPC group compared with that in the control group at the same time-points (Table II, Fig. 3A). The RI in the control group was significantly higher than that in the RIPC group at 2, 6 and $24 \mathrm{~h}$ after CPB (Table II, Fig. 3B). Furthermore, RIPC achieved a reduction in the incidence of ALI from 54.1 to $41.3 \%$ ( $\mathrm{P}=0.053$ vs. control group, Table II).

Effect of RIPC on other endpoints. The length of ICU stay was shortened by the RIPC treatment $(\mathrm{P}<0.05$, Table II). The duration of the hospital stay in the RIPC group was also short,
Table I. Comparison of clinicopathological characteristics between the two groups.

Control

\begin{tabular}{lcc} 
Characteristic & RIPC $(\mathrm{n}=121)$ & group $(\mathrm{n}=120)$ \\
\hline Age (years) & $45.2 \pm 10.06$ & $48.2 \pm 9.89$ \\
Male sex (\%) & $65(53.7)$ & $62(55.0)$ \\
Weight (kg) & $57.6 \pm 11.36$ & $55.3 \pm 9.86$ \\
Single/double valve & $72 / 49$ & $80 / 40$ \\
Left ventricular ejection & & \\
fraction $(\%)$ & & \\
$>55$ & $93(76.7)$ & $91(75.8)$ \\
$<55$ & $29(23.9)$ & $29(24.1)$ \\
NYHA class & & \\
I & $27(22.7)$ & $25(20.8)$ \\
II & $58(47.9)$ & $62(51.7)$ \\
III & $31(25.6)$ & $33(27.5)$ \\
IV & $2(1.6)$ & $2(1.7)$ \\
AVR & $22(18.1)$ & $25(20.8)$ \\
DVR & $47(38.8)$ & $47(39.2)$ \\
MVR & $53(43.8)$ & $48(40.0)$ \\
Aortic clamp time (min) & $77.87 \pm 28.09$ & $80.53 \pm 26.32$ \\
CPB time (min) & $114.07 \pm 31.04$ & $112.80 \pm 33.87$ \\
Mechanical ventilation & $8.8 \pm 3.64$ & $9.2 \pm 5.7$
\end{tabular}

time $(\mathrm{h})$

Values are expressed as the mean \pm standard deviation or $\mathrm{n}(\%)$. RIPC, remote ischaemic pre-conditioning; NYHA, New York Heart Association; AVR, aortic valve replacement; DVR, double valve replacement; MVR, mitral valve replacement; CPB, cardiac bypass surgery.

but not significant compared with that in the control group $(\mathrm{P}=0.24$, Table II). In addition, no significant difference in the occurrence rate of death, myocardial infarction and stroke was identified between the RIPC and the control group (Table II).

Effect of RIPC on inflammatory factors and oxidative stress. The release of SICAM-1 and ET-1, as well as the content of MDA increased at first in the two groups at 5 min after CPB and was further enhanced at $2 \mathrm{~h}$ (except for ET-1 in RIPC group), and declined thereafter. However, the extent of the increase of these factors was lower in the RIPC group compared with that in the control group at each corresponding time-point (Fig. 3C-E). Furthermore, the NO levels were increased by the RIPC treatment compared with that in the control group at each corresponding time-point (Fig. 3F).

\section{Discussion}

In the present prospective study, it was demonstrated that RIPC decreased the PMI of patients receiving valve replacement. Certain studies have proved that RIPC has beneficial effects in terms of reducing PMI $(27,28,30)$, which has also been demonstrated in a recent meta-analysis (36). However, no significant cardioprotective effect of RIPC was indicated in 


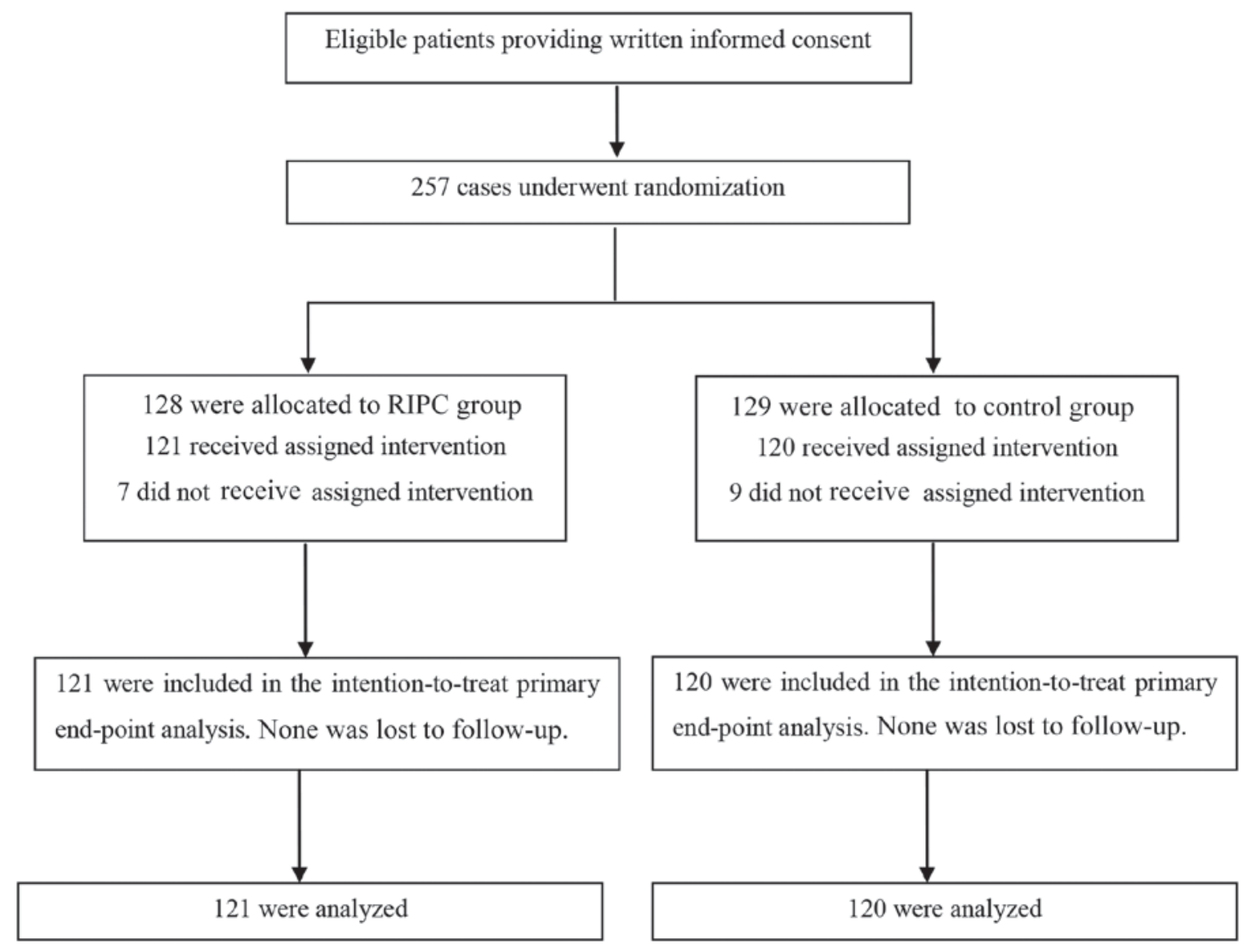

Figure 1. Flow chart depicting the randomization and follow-up of patients. Intention-to-treat analysis included 257 patients who underwent randomization. Of the 128 cases in the RIPC group, 7 did not receive the assigned intervention. In the control group, 9 out of 129 cases did not receive the assigned intervention. The remaining 241 cases for final analysis were included in the present study. RIPC, remote ischaemic pre-conditioning.

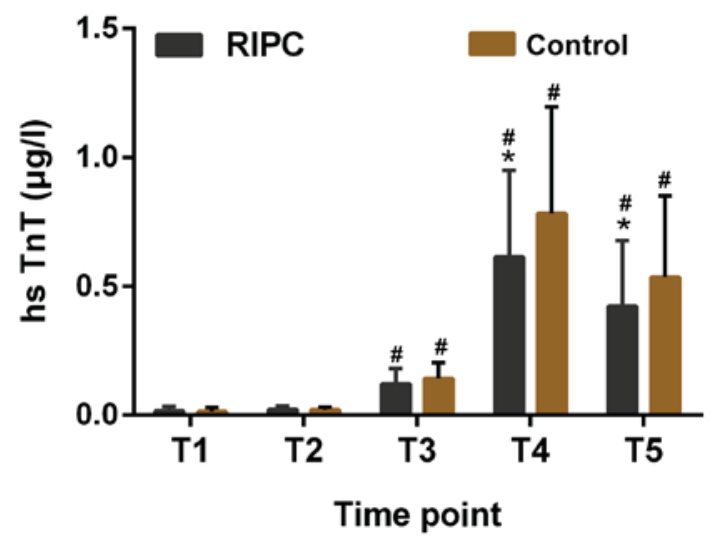

Figure 2. Serum hsTnT levels in RIPC and control groups. Time-points: T1, prior to surgery; T2, 5 min post-surgery; T3, 2 h post-surgery; T4, $6 \mathrm{~h}$ post-surgery; T5, 24 h post-surgery. ${ }^{*} \mathrm{P}<0.01$ vs. T1, ${ }^{*} \mathrm{P}<0.01$ vs. Control group at corresponding time-point. hsTnT, high-sensitivity troponin-T; RIPC, remote ischaemic pre-conditioning.

certain other previous studies $(25,37)$. Notably, RIPC may not reduce hsTnT levels, renal injury or ICU-support requirements in high-risk cardiac surgery in patients receiving generous doses of opioids as well as propofol and volatile anaesthesia, which differed from the effective trials. The intense technique used in the present study was more rapid (requires only $20 \mathrm{~min}$ ) than the standard single-limb RIPC protocol (requires $40 \mathrm{~min}$ ). Thus, it was possible to perform multi-limb RIPC prior to sternotomy. Furthermore, the different relative timing of RIPC and the concomitant therapy in patients undergoing cardiac surgery may contribute to the conflicting results among studies $(25,26,32)$.

Another conclusion of the present study was that RIPC treatment elicited protective effects on the lung. Pulmonary artery blood flow was completely disrupted under CPB, and lung $I / R$ injury was induced during this process. Post-operative pulmonary dysfunction has been identified as one of the most important factors contributing to the cardiac surgery-associated mortality (38). Pulmonary oxygenation, an important indicator for evaluating lung function when lung injury occurs, may be directly reflected by the $\mathrm{P}\left(\mathrm{A}-\mathrm{aDO}_{2}\right)$ and RI (35). In the present study, RIPC was indicated to achieve a reduction of the $\mathrm{P}\left(\mathrm{A}-\mathrm{aDO}_{2}\right)$ and $\mathrm{RI}$ after $\mathrm{CPB}$ compared with that in the control group, suggesting an improvement in the oxygenation of the patients in RIPC group. In addition, ALI may be triggered by valve replacement surgery (39). Although no significant difference was noted in comparison with the control group, the incidence of ALI was slightly reduced in the RIPC group. Furthermore, the length of ICU and hospital stays following cardiac surgery was shortened by RIPC. This result was in line with a previous study (32). In the present study, RIPC treatment also reduced kidney injury in patients after cardiac surgery $(32,40)$. All of these results proved the protective effect of RIPC on various organs. 
Table II. Summary of study endpoints.

\begin{tabular}{|c|c|c|c|c|}
\hline Endpoint & Control group $(n=120)$ & RIPC group $(n=121)$ & Mean difference $(95 \% \mathrm{CI})$ & P-value \\
\hline \multicolumn{5}{|l|}{ hsTnT $(\mu \mathrm{g} / \mathrm{l})$} \\
\hline $\mathrm{T} 1$ & $0.014 \pm 0.016$ & $0.016 \pm 0.018$ & $-0.002(-0.060$ to 0.064$)$ & $>0.999$ \\
\hline $\mathrm{T} 2$ & $0.020 \pm 0.011$ & $0.022 \pm 0.013$ & $-0.001(-0.061$ to 0.063$)$ & $>0.999$ \\
\hline $\mathrm{T} 3$ & $0.143 \pm 0.061$ & $0.122 \pm 0.059$ & $-0.021(-0.083$ to 0.041$)$ & $>0.999$ \\
\hline $\mathrm{T} 4$ & $0.783 \pm 0.412$ & $0.614 \pm 0.336$ & $-0.169(-0.231$ to -0.106$)$ & $<0.001$ \\
\hline T5 & $0.536 \pm 0.314$ & $0.423 \pm 0.254$ & $-0.113(-0.175$ to -0.050$)$ & $<0.001$ \\
\hline \multicolumn{5}{|l|}{$\mathrm{P}\left(\mathrm{A}-\mathrm{aDO}_{2}\right)(\mathrm{mmHg})$} \\
\hline $\mathrm{T} 1$ & $19.96 \pm 1.47$ & $19.09 \pm 6.61$ & $-0.8600(-10.14$ to 8.424$)$ & $>0.999$ \\
\hline $\mathrm{T} 2$ & $152.16 \pm 23.80$ & $89.98 \pm 28.70$ & $-62.18(-71.46$ to -52.90$)$ & $<0.001$ \\
\hline $\mathrm{T} 3$ & $182.70 \pm 47.74$ & $142.3 \pm 33.17$ & $-40.32(-49.60$ to -31.04$)$ & $<0.001$ \\
\hline $\mathrm{T} 4$ & $137.94 \pm 31.15$ & $121.6 \pm 31.54$ & $-16.29(-25.57$ to -7.006$)$ & $<0.001$ \\
\hline T5 & $82.83 \pm 26.60$ & $56.02 \pm 18.89$ & $-26.81(-36.09$ to -17.53$)$ & $<0.001$ \\
\hline \multicolumn{5}{|l|}{ RI } \\
\hline $\mathrm{T} 1$ & $0.255 \pm 0.14$ & $0.258 \pm 0.08$ & $0.003(-0.079$ to 0.085$)$ & $>0.999$ \\
\hline $\mathrm{T} 2$ & $0.318 \pm 0.11$ & $0.292 \pm 0.09$ & $-0.026(-0.108$ to 0.056$)$ & $>0.999$ \\
\hline $\mathrm{T} 3$ & $1.538 \pm 0.75$ & $0.629 \pm 0.20$ & $-0.909(-0.991$ to -0.826$)$ & $<0.001$ \\
\hline $\mathrm{T} 4$ & $1.057 \pm 0.34$ & $0.739 \pm 0.22$ & $-0.318(-0.400$ to -0.235$)$ & $<0.001$ \\
\hline $\mathrm{T} 5$ & $0.646 \pm 0.38$ & $0.403 \pm 0.12$ & $-0.243(-0.325$ to -0.160$)$ & $<0.001$ \\
\hline ALI & $65(54.1)$ & $50(41.3)$ & NA & $0.053^{\mathrm{a}}$ \\
\hline ICU stay (h) & $72.28 \pm 10.5$ & $53.59 \pm 8.45$ & NA & $<0.001^{\mathrm{b}}$ \\
\hline Hospital stay (days) & $17.56 \pm 3.64$ & $16.98 \pm 4.01$ & NA & $0.241^{\mathrm{b}}$ \\
\hline \multicolumn{5}{|c|}{ Clinical outcome at 90 days } \\
\hline Death & $4(3.3)$ & $2(1.65)$ & NA & $0.446^{\mathrm{c}}$ \\
\hline Myocardial infarction & $2(1.67)$ & $1(0.83)$ & NA & $0.662^{\mathrm{c}}$ \\
\hline Stroke & $1(0.83)$ & $1(0.83)$ & NA & $1.000^{\mathrm{c}}$ \\
\hline
\end{tabular}

Mean differences, 95\% CIs of the differences and P-values in different times of hsTnT, $\mathrm{P}\left(\mathrm{A}-\mathrm{aDO} \mathrm{O}_{2}\right)$ and RI levels were analyzed by two-way

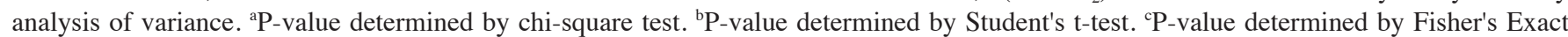
test. Values are expressed as the mean \pm standard deviation or $\mathrm{n}(\%)$. Time-points: T1, prior to surgery; $\mathrm{T} 2,5$ min post-surgery; T3, $2 \mathrm{~h}$ post-surgery; $\mathrm{T} 4,6 \mathrm{~h}$ post-surgery; $\mathrm{T} 5,24 \mathrm{~h}$ post-surgery. hsTnT, high-sensitive troponin- $\mathrm{T} ; \mathrm{P}\left(\mathrm{A}-\mathrm{aDO}_{2}\right)$, alveolar-arterial oxygen pressure difference; RI, respiratory index; ICU, intensive care unit; RIPC, remote ischaemic pre-conditioning; NA, not applicable; ALI, acute lung injury; CI, confidence interval.

Although the mechanisms underlying the protective effect of RIPC remain to be fully elucidated, a mechanistic model for the interaction between the pre-conditioned limb and the remote organ has been proposed $(22,41)$. Previous studies have demonstrated that ischemic pre-conditioning suppressed the inflammatory response and improved the anti-oxidant capacity of tissues $(42,43)$. In addition, the lung is highly susceptible to oxidative stress due to its large surface area (44). The effect of RIPC on the inflammation status and oxidation was then investigated in the present study. The results indicated that the release of sICAM-1 and ET-1 was mitigated and the content of lipid peroxidation product MDA after CPB was decreased by RIPC. These results indicated that RIPC produced a protective effect through inhibiting SIRS and oxidative stress in lung tissues. Furthermore, the decreased ET-1 in the RIPC group also suggested that the strength of myocardial constriction was closely associated with blood vessels. NO is a vasoactive factor and has relaxation effects, which were contrary to ET-1 (45). Consistently, it increased production of NO in the RIPC group, pointing to the improvement of pulmonary vascular tension. Taken together, it was concluded that RIPC elicits a protective effect by reducing the inflammatory status and improving the anti-oxidant capacity.

A limitation of the present study was that the effect of RIPC was not assessed in children, as all subjects were adult patients. The small-scale cohort and single-center design of the present study were further limitations of this study. Undoubtedly, the effect of RIPC should be explored on a larger scale and subjects should be recruited from multiple medical centers.

In conclusion, the present study demonstrated that RIPC alleviated PMI and lung I/R injury and may improve clinical outcomes, including shortened ICU stay, decreased hsTnT level at 6 and $24 \mathrm{~h}$ post-surgery, decreased $\mathrm{P}\left(\mathrm{A}-\mathrm{aDO}_{2}\right)$ level beginning from 5 min post-surgery and decreased RI level beginning from $2 \mathrm{~h}$ post-surgery, in adult patients undergoing valve replacement. The protective effect of RIPC may be 

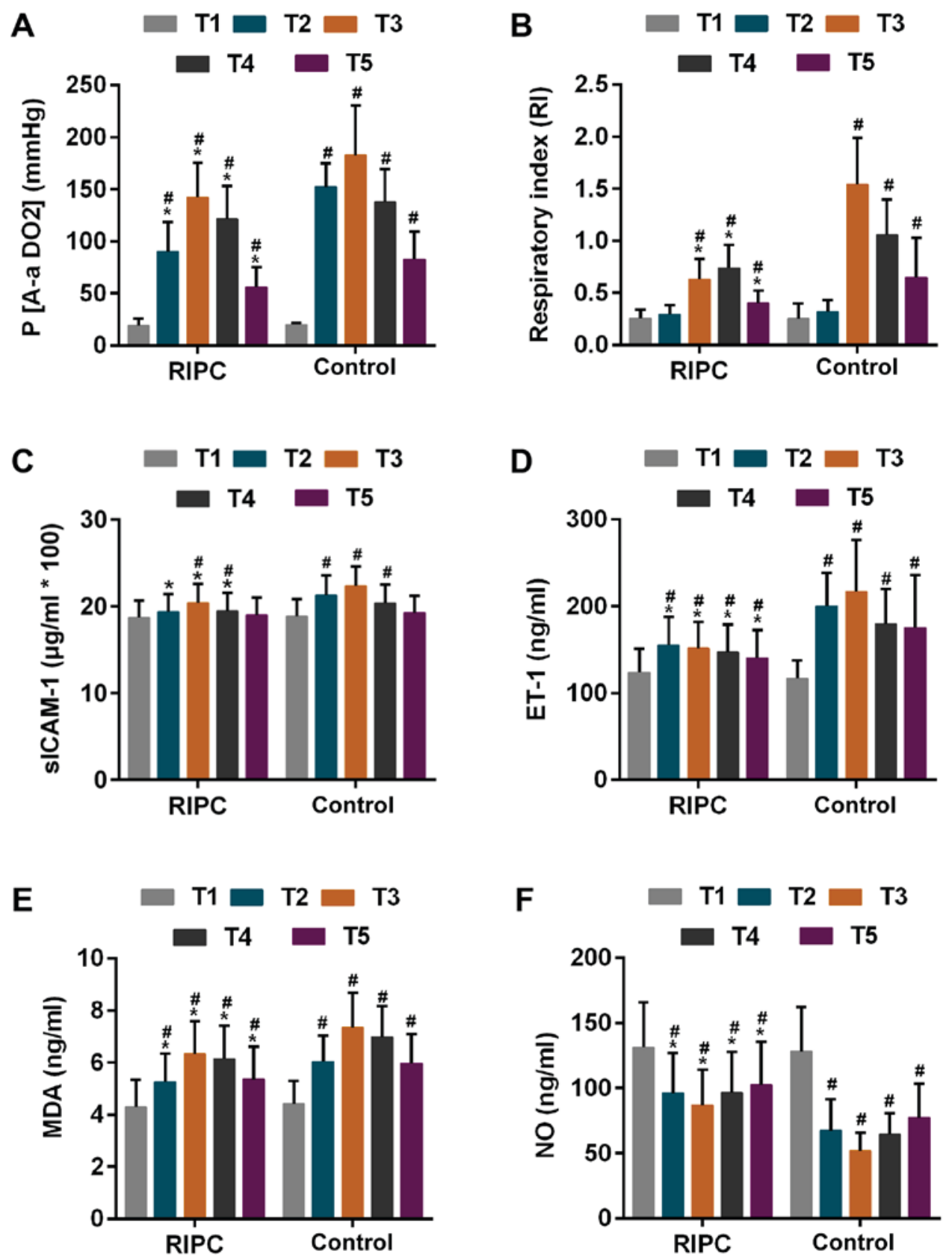

Figure 3. Parameters in the two groups at different time-points. (A and B) Oxygen supply represented by (A) $\mathrm{P}\left(\mathrm{A}-\mathrm{aDO} \mathrm{O}_{2}\right.$ ) and (B) RI. (C and D) Alteration of serum markers for inflammation represented by (C) sICAM-1 and (D) ET-1. (E) Estimation of oxidative stress via determination of MDA content. (F) Release of NO in RIPC and control group groups Time-points: T1, prior to surgery; T2, 5 min post-surgery; T3, $2 \mathrm{~h}$ post-surgery; T4, $6 \mathrm{~h}$ post-surgery; T5, $24 \mathrm{~h}$ post-surgery. ${ }^{*} \mathrm{P}<0.01$ vs. $\mathrm{T} 1,{ }^{\prime \prime} \mathrm{P}<0.01$ vs. Control group at corresponding time-point. $\mathrm{P}\left(\mathrm{A}-\mathrm{aDO} \mathrm{O}_{2}\right)$, alveolar-arterial oxygen pressure difference; $\mathrm{RI}$, respiratory index; sICAM-1, soluble intercellular adhesion molecule-1; ET-1, endothelin-1; MDA, malondialdehyde; NO, nitric oxide; RIPC, remote ischaemic pre-conditioning.

associated with the reduction of inflammation and oxidative stress. However, large-scale and multi-center randomized controlled trials should be performed in order to confirm the precise effects of RIPC.

\section{Acknowledgements}

None.

\section{Funding}

No funding was received.

\section{Availability of data and materials}

Not applicable.

\section{Authors' contributions}

XL and LW made substantial contributions to the conception and design of the present study. LL and XZ were responsible for acquisition, analysis and interpretation of data. $\mathrm{XJ}$ and $\mathrm{XZ}$ were responsible for drafting the article and critically revising it for important intellectual content. All authors provided final approval of the version to be published. 


\section{Ethical approval and consent to participate}

The present randomized controlled trial was approved by the Ethics Committee of the First Affiliated Hospital of Wenzhou Medical University (Wenzhou, China). Written informed consent was provided by each of the patients included.

\section{Patient consent for publication}

Not applicable.

\section{Competing interests}

The authors declare that they have no competing interests.

\section{References}

1. Ignarro LJ, Buga GM, Wood KS, Byrns RE and Chaudhuri G: Endothelium-derived relaxing factor produced and released from artery and vein is nitric oxide. Proc Natl Acad Sci USA 84: 9265-9269, 1987.

2. Yanagisawa M, Kurihara H, Kimura S, Tomobe Y, Kobayashi M, Mitsui Y, Yazaki Y, Goto K and Masaki T: A novel potent vasoconstrictor peptide produced by vascular endothelial cells. Nature 332: 411-415, 1988.

3. Jalowy A, Schulz R and Heusch G: AT1 receptor blockade in experimental myocardial ischemia/reperfusion. J Am Soc Nephrol 10 (Suppl 11): S129-S136, 1999.

4. Kubota I, Han X, Opel DJ, Zhao YY, Baliga R, Huang P, Fishman MC, Shannon RP, Michel T and Kelly RA: Increased susceptibility to development of triggered activity in myocytes from mice with targeted disruption of endothelial nitric oxide synthase. J Mol Cell Cardiol 32: 1239-1248, 2000.

5. Bolli R: Cardioprotective function of inducible nitric oxide synthase and role of nitric oxide in myocardial ischemia and preconditioning: An overview of a decade of research. J Mol Cell Cardiol 33: 1897-1918, 2001.

6. Yang XM, Proctor JB, Cui L, Krieg T, Downey JM and Cohen MV: Multiple, brief coronary occlusions during early reperfusion protect rabbit hearts by targeting cell signaling pathways. J Am Coll Cardiol 44: 1103-1110, 2004.

7. Liu X, Chen H, Zhan B, Xing B, Zhou J, Zhu H and Chen Z: Attenuation of reperfusion injury by renal ischemic postconditioning: The role of NO. Biochem Biophys Res Commun 359: 628-634, 2007.

8. Hasdai D, Kornowski R and Battler A: Endothelin and myocardial ischemia. Cardiovasc Drugs Ther 8: 589-599, 1994

9. Lang SC, Elsässer A, Scheler C, Vetter S, Tiefenbacher CP, Kübler W, Katus HA and Vogt AM: Myocardial preconditioning and remote renal preconditioning-identifying a protective factor using proteomic methods? Basic Res Cardiol 101: 149-158, 2006 .

10. Zhou W, Zeng D, Chen R, Liu J, Yang G, Liu P and Zhou X: Limb ischemic preconditioning reduces heart and lung injury after an open heart operation in infants. Pediatr Cardiol 31: 22-29, 2010.

11. Tuttolomondo A, Pecoraro R, Casuccio A, Di Raimondo D, Buttà C, Clemente G, Della Corte V, Guggino G, Arnao V, Maida C, et al: Peripheral frequency of CD4+ CD28- cells in acute ischemic stroke: Relationship with stroke subtype and severity markers. Medicine (Baltimore) 94: e813, 2015.

12. Tuttolomondo A, Pedone C, Pinto A, Di Raimondo D, Fernandez P, Di Sciacca R and Licata G; Gruppo Italiano di Farmacoepidemiologia dell'Anziano (GIFA) researchers: Predictors of outcome in acute ischemic cerebrovascular syndromes: The GIFA study. Int J Cardiol 125: 391-396, 2008.

13. Di Raimondo D, Tuttolomondo A, Buttà C, Miceli S, Licata G and Pinto A: Effects of ACE-inhibitors and angiotensin receptor blockers on inflammation. Curr Pharm Des 18: 4385-4413, 2012.

14. Przepiera-Będzak H, Fischer K and Brzosko M: Serum interleukin-18, Fetuin-A, soluble intercellular adhesion molecule-1, and endothelin-1 in ankylosing spondylitis, psoriatic arthritis and SAPHO syndrome. Int J Mol Sci 17: pii: E1255, 2016.

15. Dröge W: Free radicals in the physiological control of cell function. Physiol Rev 82: 47-95, 2002.
16. Lønborg J, Kelbaek H, Vejlstrup N, Jørgensen E, Helqvist S, Saunamäki K, Clemmensen $\mathrm{P}$, Holmvang L, Treiman M, Jensen JS and Engstrøm T: Cardioprotective effects of ischemic postconditioning in patients treated with primary percutaneous coronary intervention, evaluated by magnetic resonance. Circ Cardiovasc Interv 3: 34-41, 2010.

17. Hashmi MA, Ahsan B, Shah SIA and Khan MIU: Antioxidant capacity and lipid peroxidation product in pulmonary tuberculosis. Al Ame en J Med Sci 5: 313-319, 2012.

18. Muehlschlegel JD, Perry TE, Liu KY, Nascimben L, Fox AA, Collard CD, Avery EG, Aranki SF, D'Ambra MN, Shernan SK, et al: Troponin is superior to electrocardiogram and creatinine kinase MB for predicting clinically significant myocardial injury after coronary artery bypass grafting. Eur Heart J 30: 1574-1583, 2009.

19. Erdil N, Eroglu T, Akca B, Disli OM, Yetkin O, Colak MC, Erdil $\mathrm{F}$ and Battaloglu B: The effects of $\mathrm{N}$-acetylcysteine on pulmonary functions in patients undergoing on-pump coronary artery surgery: A double blind placebo controlled study. Eur Rev Med Pharmacol Sci 20: 180-187, 2016.

20. Bonservizi WG, Koike MK, Saurim R, Felix GA, da Silva SM, Montero EF and Taha MO: Ischemic preconditioning and atenolol on lung injury after intestinal ischemia and reperfusion in rats. Transplant Proc 46: 1862-1866, 2014.

21. Przyklenk K, Bauer B, Ovize M, Kloner RA and Whittaker P: Regional ischemic 'preconditioning' protects remote virgin myocardium from subsequent sustained coronary occlusion. Circulation 87: 893-899, 1993.

22. Hausenloy DJ and Yellon DM: Remote ischaemic preconditioning: Underlying mechanisms and clinical application. Cardiovasc Res 79: 377-386, 2008.

23. Sivaraman V, Pickard JM and Hausenloy DJ: Remote ischaemic conditioning: Cardiac protection from afar. Anaesthesia 70: 732-748, 2015.

24. Heusch G, Bøtker HE, Przyklenk K, Redington A and Yellon D: Remote ischemic conditioning. J Am Coll Cardiol 65: 177-195, 2015.

25. Young PJ, Dalley P, Garden A, Horrocks C, La Flamme A, Mahon B, Miller J, Pilcher J, Weatherall M, Williams J, et al: A pilot study investigating the effects of remote ischemic preconditioning in high-risk cardiac surgery using a randomised controlled double-blind protocol. Basic Res Cardiol 107: 256, 2012.

26. Rahman IA, Mascaro JG, Steeds RP, Frenneaux MP, Nightingale P, Gosling P, Townsend P, Townend JN, Green D and Bonser RS: Remote ischemic preconditioning in human coronary artery bypass surgery: From promise to disappointment? Circulation 122: 926667, 2010.

27. Venugopal V, Hausenloy DJ, Ludman A, Di Salvo C, Kolvekar S, Yap J, Lawrence D, Bognolo J and Yellon DM: Remote ischaemic preconditioning reduces myocardial injury in patients undergoing cardiac surgery with cold-blood cardioplegia: A randomised controlled trial. Heart 95: 1567-1571, 2009.

28. Hausenloy DJ, Mwamure PK, Venugopal V, Harris J, Barnard M, Grundy E, Ashley E, Vichare S, Di Salvo C, Kolvekar S, et al: Effect of remote ischaemic preconditioning on myocardial injury in patients undergoing coronary artery bypass graft surgery: A randomised controlled trial. Lancet 370: 575-579, 2007.

29. Ali N, Rizwi F, Iqbal A and Rashid A: Induced remote ischemic pre-conditioning on ischemia-reperfusion injury in patients undergoing coronary artery bypass. J Coll Physicians Surg Pak 20: 427-431, 2010 .

30. Thielmann M, Kottenberg E, Boengler K, Raffelsieper C, Neuhaeuser M, Peters J, Jakob H and Heusch G: Remote ischemic preconditioning reduces myocardial injury after coronary artery bypass surgery with crystalloid cardioplegic arrest. Basic Res Cardiol 105: 657-664, 2010.

31. Hoole SP, Heck PM, Sharples L, Khan SN, Duehmke R, Densem CG, Clarke SC, Shapiro LM, Schofield PM, O'Sullivan M and Dutka DP: Cardiac remote ischemic preconditioning in coronary stenting (CRISP Stent) study: A prospective, randomized control trial. Circulation 119: 820-827, 2009.

32. Candilio L, Malik A, Ariti C, Barnard M, Di Salvo C, Lawrence D, Hayward M, Yap J, Roberts N, Sheikh A, et al: Effect of remote ischaemic preconditioning on clinical outcomes in patients undergoing cardiac bypass surgery: A randomised controlled clinical trial. Heart 101: 185-192, 2015.

33. Lopez-Calle E, Espindola P, Spinke J, Lutz S, Nichtl A, Tgetgel A, Herbert N, Marcinowski M, Klepp J, Fischer T, et al: A new immunochemistry platform for a guideline-compliant cardiac troponin $\mathrm{T}$ assay at the point of care: proof of principle. Clin Chem Lab Med 55: 1798-1804, 2017. 
34. Bernard GR, Artigas A, Brigham KL, Carlet J, Falke K, Hudson L, Lamy M, Legall JR, Morris A and Spragg R: The American-European consensus conference on ARDS Definitions, mechanisms, relevant outcomes and clinical tria coordination. Am J Respir Crit Care Med 149: 818-824, 1994.

35. Zhang C, Gong W, Liu H, Guo Z and Ge S: Inhibition of matrix metalloproteinase-9 with low-dose doxycycline reduces acute lung injury induced by cardiopulmonary bypass. Int J Clin Exp Med 7: 4975-4982, 2014.

36. Pilcher JM, Young P, Weatherall M, Rahman I, Bonser RS and Beasley RW: A systematic review and meta-analysis of the cardioprotective effects of remote ischaemic preconditioning in open cardiac surgery. J R Soc Med 105: 436-445, 2012.

37. Karuppasamy P, Chaubey S, Dew T, Musto R, Sherwood R, Desai J, John L, Shah AM, Marber MS and Kunst G: Remote intermittent ischemia before coronary artery bypass graft surgery: A strategy to reduce injury and inflammation? Basic Res Cardiol 106: 511-519, 2011.

38. Adabag AS, Wassif HS, Rice K, Mithani S, Johnson D, Bonawitz-Conlin J, Ward HB, McFalls EO, Kuskowski MA and Kelly RF: Preoperative pulmonary function and mortality after cardiac surgery. Am Heart J 159: 691-697, 2010.

39. Mazzeffi M, Kassa W, Gammie J, Tanaka K, Roman P, Zhan M, Griffith B and Rock P: Preoperative aspirin use and lung injury after aortic valve replacement surgery: A retrospective cohort study. Anesth Analg 121: 271-277, 2015.

40. Zimmerman RF, Ezeanuna PU, Kane JC, Cleland CD, Kempananjappa TJ, Lucas FL and Kramer RS: Ischemic preconditioning at a remote site prevents acute kidney injury in patients following cardiac surgery. Kidney Int 80: 861-867, 2011.
41. Karu I, Tahepold P, Ruusalepp A, Reimann E, Koks S and Starkopf J: Exposure to sixty min of hyperoxia upregulates myocardial humanins in patients with coronary artery disease-a pilot study. J Physiol Pharmacol 66: 899-906, 2015.

42. Pinheiro DF, Fontes B, Shimazaki JK, Heimbecker AM, Jacysyn Jde F, Rasslan S, Montero EF and Utiyama EM: Ischemic preconditioning modifies mortality and inflammatory response. Acta Cir Bras 31: 1-7, 2016.

43. Ucar G, Topaloglu E, Kandilci HB and Gümüsel B: Effect of ischemic preconditioning on reactive oxygen species-mediated ischemia-reperfusion injury in the isolated perfused rat lung. Clin Biochem 38: 681-684, 2005.

44. Imai Y, Kuba K, Neely GG, Yaghubian-Malhami R, Perkmann T, van Loo G, Ermolaeva M, Veldhuizen R, Leung YH, Wang H, et al: Identification of oxidative stress and Toll-like receptor 4 signaling as a key pathway of acute lung injury. Cell 133: 235-249, 2008.

45. Victorino GP, Wisner DH and Tucker VL: Basal release of nitric oxide and its interaction with endothelin-1 on single vessel hydraulic permeability. J Trauma 50: 535-539, 2001.

This work is licensed under a Creative Commons Attribution-NonCommercial-NoDerivatives 4.0 International (CC BY-NC-ND 4.0) License. 